\title{
Effect of diabetes mellitus on postoperative outcomes in patients undergoing emergency general surgery procedures.
}

\author{
Abdulmalik Altaf* \\ Department of Surgery, Faculty of Medicine, King Abdulaziz University, Jeddah, Saudi Arabia
}

\begin{abstract}
Background: Diabetes Mellitus (DM) is a global health hazard affecting millions of people globally. A nationwide study conducted in Saudi Arabia showed the incidence and prevalence of DM were gradually increasing. Studies on the outcomes of emergency general surgery operations of diabetic patients are limited. The objective of this study is to compare the outcomes of diabetic patients undergoing emergency general surgery operations compared to those who are non-diabetic.

Methods: Data for this cross-sectional study were collected using an observational clinical case series database, retrospectively, for patients undergoing emergency general surgery operations between July 2017 and December 2018 at King Abdulaziz University Hospital, Jeddah, Saudi Arabia. Patients were classified into diabetic and non-diabetic groups based on previous diagnosis at the time of presentation for their emergency procedure. Statistical analysis was utilized to investigate the association of diabetes with factors related to morbidity and mortality.

Results: The total number of the participants was 325, wherein $177(54.5 \%)$ were males. $185(57 \%)$ were diabetic. We found significant association between diabetes mellitus and ICU admission and hospital readmissions compared to non-diabetic patients (odds ratio 1.772 , relative risk 1.257 vs. $0.709, \mathrm{p}=0.025$ ). However, no statistically significant association was found between the diagnosis of diabetes and inhospital or 30-day mortality after emergency general surgery procedures.

Conclusion: There are significant associations of the diagnosis of diabetes and worse postoperative outcomes in patients undergoing emergency general surgery procedures. Health care providers should give special attention as well as prompt and watchful perioperative care for this patients' population.
\end{abstract}

Keywords: Diabetes mellitus, Emergency surgery, Postoperative complications, Postoperative morbidity, Postoperative mortality, Surgical outcomes, Postoperative outcomes.

Accepted on August 19, 2019

\section{Introduction}

Diabetes Mellitus (DM) is a global health hazard with nearly 150 million cases around the world. The World Health Organization has estimated that the number of diabetic patients will increase to about 366 million by 2030 , with the majority of them being from the developing countries [1,2]. A nationwide study conducted in Saudi Arabia carried out the first comprehensive review of the incidence and prevalence rates of $\mathrm{DM}$ and found that the prevalence rates of diabetes were gradually increasing [3].

Hyperglycemia of DM disturbs many body functions including wound healing and body response to surgical trauma [4-7]. On the other hand, patients undergoing emergency surgical procedures represent a high-risk population [8]. Thus, the outcomes of diabetic patients undergoing emergency general surgery procedures might be different from non-diabetic patients. Recognizing such a difference might be helpful for both diabetic patients and their prospective physicians and health care providers. In this study, we aim to compare the outcomes of diabetic patients undergoing emergency general surgery operations compared to those who are non-diabetic.

\section{Materials and Methods}

\section{Study design}

This cross-sectional study was conducted at King Abdulaziz University Hospital (KAUH), Jeddah, Saudi Arabia. Data was collected and derived from an observational clinical case series database. We retrospectively analysed the data of patients registered between July 2017 and December 2018. The study was approved by the Institutional Review Board of KAUH. The data of all the patients who underwent emergency general surgical operations from July 2017 to December 2018 was obtained from the medical records and operation reports in KAUH. We excluded patients who underwent any related elective general surgery procedure within 30-days prior to the emergency procedure. 


\section{Data collection}

Baseline demographic and clinical data were retrieved from medical records. These included basic information such as age, sex, body mass index (BMI), smoking status, American Society of Anesthesiologists (ASA) score, as well as clinical information such as previous diagnosis of DM at the time of presentation for the emergency procedure, Ischemic Heart Disease (IHD), heart failure, cerebrovascular disease, cancer, Chronic Kidney Disease (CKD), and Chronic Obstructive Pulmonary Disease (COPD). Patients were classified into diabetic and non-diabetic groups based on previous diagnosis at the time of presentation for the emergency surgical procedure. Regarding obesity, WHO classification was used to categorize patients according to their body mass index [9]. The primary endpoint was postoperative 30-days mortality. To analyze the morbidity and mortality outcomes, factors contributing to postoperative morbidity were also reviewed such as the presence of postoperative complications, e.g. wound infections, pneumonia, thromboembolic events, cardiovascular and cerebrovascular events, ICU-admission, hospital readmission, emergency room visits, and the need for repeated surgery.

\section{Statistical methods}

Statistical analysis was performed using the Statistical Package for Social Sciences version 24.0 for Windows (SPSS Inc., Chicago, IL, USA). Chi square test was carried out to analyze the association, odds ratio, and relative risk of diabetes mellitus with baseline parameters (demographics and comorbidities), morbidity and mortality factors.

\section{Results}

A total of 325 patients were identified having had emergency general surgery operations during the study period. Demographic data of the participants has been documented in Table 1. Out of the total number of participants, $177(54.5 \%)$ were males. Patients' pre-existing various medical diagnoses were also documented in Table 1. It can be noticed that 185 $(56.9 \%)$ of patients were known diabetics at the time of their emergency procedure. Table 2 shows the types of emergency surgery and the patients' ASA classification scores. Most of the emergency general surgery procedures, 204 (62.8\%), were for abdominal pathology. Most of the patients were class III or less according to the ASA classification.

Table 1. Patients' demographics and known clinical characteristics.

\begin{tabular}{|c|c|c|c|}
\hline Variables & & Count & Percent \\
\hline \multirow[t]{2}{*}{ Total } & & 325 & 100 \\
\hline & Male & 177 & 54.5 \\
\hline \multirow[t]{2}{*}{ Gender } & Female & 148 & 45.5 \\
\hline & Adult & 204 & 62.8 \\
\hline \multirow[t]{4}{*}{ Age } & Elder & 121 & 37.2 \\
\hline & Underweight & 12 & 3.7 \\
\hline & Normal & 106 & 32.6 \\
\hline & Overweight & 101 & 31.1 \\
\hline $\mathrm{BMI}^{*}$ Class & Obese I, II, III & 106 & 32.6 \\
\hline Ischemic heart disease & & 61 & 18.8 \\
\hline Heart failure & & 27 & 8.3 \\
\hline Cerebrovascular disease & & 31 & 9.5 \\
\hline Diabetes mellitus & & 185 & 56.9 \\
\hline Hypertension & & 172 & 52.9 \\
\hline Chronic renal disease & & 33 & 10.2 \\
\hline Chronic obstructive pulmonary disease & & 4 & 1.2 \\
\hline Cancer & & 49 & 15.1 \\
\hline Smoking & & 45 & 13.8 \\
\hline
\end{tabular}

*BMI: Body Mass Index

Table 3 shows the association of different demographics and clinical characteristics with the diagnosis of DM. Not surprisingly, patients who underwent emergency surgery for diabetic foot and soft tissue infections were more likely to have 
DM. In addition, the results from the samen Table show that patients with some comorbid diseases are more likely to have DM including IHD, heart failure, cerebrovascular disease, HTN, CRD, cancer as well as those who are smokers $(\mathrm{p}<0.05)$.

Table 4 demonstrate a comparison of the association of different postoperative morbidity and mortality factors in diabetic versus non-diabetic patients. We can see clearly that ICU admission and hospital re-admission were more likely to occur in patients with DM $(\mathrm{p}<0.05)$. However, no statistically significant difference was found between the two groups regarding in-hospital or postoperative 30-day mortality.

Table 2. Type of emergency surgery and patients' ASA* score.

\begin{tabular}{|c|c|c|c|}
\hline Variables & & Count & Percent \\
\hline \multirow[t]{4}{*}{ Total } & & 325 & 100 \\
\hline & Abdominal (gastrointestinal, hepatobiliary, hernia) & 204 & 62.8 \\
\hline & Diabetic foot & 75 & 23.1 \\
\hline & Soft Tissue Infection & 24 & 7.3 \\
\hline \multirow[t]{5}{*}{ Type of Emergency Surgery } & Others (e.g. breast, perianal etc..) & 22 & 6.8 \\
\hline & ASA I & 120 & 36.9 \\
\hline & ASA II & 88 & 27.2 \\
\hline & ASA III & 83 & 25.5 \\
\hline & ASA IV & 32 & 9.8 \\
\hline ASA & ASA V & 2 & 0.6 \\
\hline
\end{tabular}

*ASA: American Society of Anaesthesiologists Score

Table 3. Association between having a diagnosis of DM with demographics, type of surgery and chronic medical conditions.

\begin{tabular}{|c|c|c|c|c|c|c|c|c|}
\hline & & \multirow[b]{2}{*}{$\mathbf{N}$} & \multicolumn{2}{|c|}{ Diabetes mellitus } & \multirow{2}{*}{$\begin{array}{l}\text { OR } \\
\text { Yes }\end{array}$} & \multicolumn{2}{|c|}{ Relative risk } & \multirow[t]{2}{*}{$p$ value } \\
\hline \multicolumn{2}{|c|}{ Factor characteristics } & & Yes & No & & No & & \\
\hline \multicolumn{9}{|c|}{ Demographics } \\
\hline & Adult & 204 & $108(33.2)$ & $96(29.5)$ & 0.643 & 0.832 & 1.294 & 0.06 \\
\hline \multirow[t]{2}{*}{ Age } & Elderly (>60 year) & 121 & $77(23.7)$ & $44(13.5)$ & 1.556 & 1.202 & 0.773 & \\
\hline & Male & 177 & $107(33.0))$ & $70(21.5)$ & 1.372 & 1.147 & 0.836 & 0.16 \\
\hline \multirow[t]{4}{*}{ Gender } & Female & 148 & $78(24.0)$ & $70(21.5)$ & 0.729 & 0.872 & 1.196 & \\
\hline & Underweight & 12 & $6(1.8)$ & $6(1.8)$ & 0.748 & 0.874 & 1.168 & 0.208 \\
\hline & Normal & 106 & $58(17.8)$ & $48(14.8)$ & 0.875 & 0.943 & 1.078 & \\
\hline & Overweight & 101 & $52(16.0)$ & $49(15.1)$ & 0.726 & 0.867 & 1.194 & \\
\hline \multirow[t]{4}{*}{$\mathrm{BMI}^{*}$ Class } & Obese I, II, III & 106 & $69(21.2)$ & $37(11.4)$ & 1.656 & 1.229 & 0.742 & \\
\hline & Abdomen & 204 & $88(27.1)$ & $116(35.7)$ & 0.162 & 0.522 & 3.276 & $<0.001^{*}$ \\
\hline & Diabetic Foot & 75 & $75(23.1)$ & 0 & - & 2.212 & 0 & \\
\hline & Soft Tissue & 24 & $18(5.5)$ & $6(1.8)$ & 2.314 & 1.328 & 0.754 & \\
\hline Diagnosis & Other & 22 & $7(2.2)$ & $15(4.6)$ & 0.311 & 0.533 & 1.876 & \\
\hline \multicolumn{9}{|c|}{ Patient disease history } \\
\hline \multicolumn{2}{|c|}{ Ischemic heart disease } & 61 & $53(86.9)$ & $8(13.1)$ & 6.625 & 1.738 & 0.262 & $<0.001^{*}$ \\
\hline \multicolumn{2}{|c|}{ Heart Failure } & 27 & $23(85.2)$ & $4(14.8)$ & 4.827 & 1.567 & 0.325 & $0.002^{*}$ \\
\hline \multicolumn{2}{|c|}{ Cerebrovascular disease } & 31 & $30(96.8)$ & $1(3.2)$ & 26.903 & 1.836 & 0.068 & $<0.001^{*}$ \\
\hline
\end{tabular}




\begin{tabular}{llllllll}
\hline Hypertension & 172 & $135(78.5)$ & $37(21.5)$ & 7.516 & 2.402 & 0.32 & $<0.001^{*}$ \\
\hline Chronic renal disease & 33 & $26(78.8)$ & $7(21.2)$ & 3.107 & 1.447 & 0.466 & $0.007^{*}$ \\
\hline Chronic obstructive pulmonary disease & 4 & $2(50.0)$ & $2(50.0)$ & 0.754 & 0.877 & 1.163 & 0.778 \\
\hline Smoking & 45 & $33(73.3)$ & $12(26.7)$ & 2.316 & 1.351 & 0.583 & $0.017^{*}$ \\
\hline Cancer & 49 & $23(46.9)$ & $26(53.1)$ & 0.623 & 0.8 & 1.285 & 0.126 \\
\hline
\end{tabular}

*BMI: Body Mass Index

Table 4. Association between DM and different morbidity and mortality factors.

\begin{tabular}{|c|c|c|c|c|c|c|c|}
\hline \multirow[b]{2}{*}{ Factor characteristics } & \multirow[b]{2}{*}{$\mathbf{N}$} & \multicolumn{2}{|c|}{ Diabetes mellitus } & \multirow{2}{*}{$\begin{array}{c}\text { OR } \\
\text { Yes }\end{array}$} & \multicolumn{2}{|c|}{ Relative risk } & \multirow[t]{2}{*}{ p value } \\
\hline & & Yes & No & & No & & \\
\hline \multicolumn{8}{|l|}{ Mortality factors } \\
\hline Dead within 30 days postoperative & 44 & $29(65.9)$ & $15(34.1)$ & 1.549 & 1.187 & 0.766 & 0.195 \\
\hline Death related to operative & 25 & $15(60.0)$ & $10(40.0)$ & 0.536 & 0.814 & 1.52 & 0.343 \\
\hline \multicolumn{8}{|l|}{ Postoperative complications } \\
\hline Mechanical complication & 20 & $13(65.0)$ & $7(35.0)$ & 1.436 & 1.153 & 0.803 & 0.451 \\
\hline Neurological complication & 6 & $3(50.0)$ & $3(50.0)$ & 0.753 & 0.876 & 1.164 & 0.73 \\
\hline Pulmonary complication & 32 & $18(56.3)$ & $14(43.8)$ & 0.97 & 0.987 & 1.017 & 0.935 \\
\hline Cardiovascular complication & 7 & $4(57.1)$ & $3(42.9)$ & 1.009 & 1.004 & 0.995 & 0.991 \\
\hline Gastrointestinal complications & 8 & $5(62.5)$ & $3(37.5)$ & 1.269 & 1.101 & 0.868 & 0.747 \\
\hline Infectious complications & 46 & $32(69.6)$ & $14(30.4)$ & 1.832 & 1.253 & 0.683 & 0.075 \\
\hline Haematological complications & 3 & $1(33.3)$ & $2(66.7)$ & 0.365 & 0.577 & 1.579 & 0.394 \\
\hline \multicolumn{8}{|l|}{ Morbidity factors } \\
\hline $\mathrm{ICU}^{*}$ admission & 93 & $62(66.7)$ & $31(33.3)$ & 1.772 & 1.257 & 0.709 & $0.025^{\star}$ \\
\hline Hospital readmission & 2 & $2(100.0)$ & 0 & - & - & - & $0.005^{*}$ \\
\hline $\mathrm{ER}^{* \star}$ visit within 30 days & 30 & $19(63.3)$ & $11(36.7)$ & 1.342 & 1.126 & 0.839 & 0.457 \\
\hline Re-operation at same admission & 36 & $21(58.3)$ & $15(41.7)$ & 1.059 & 1.024 & 0.968 & 0.874 \\
\hline In-hospital mortality & 1 & $1(100.0)$ & - & 4 & - & - & 0.134 \\
\hline
\end{tabular}

*ICU: Intensive Care Unit; *ER: Emergency Room

\section{Discussion}

Diabetes mellitus is considered a general term for heterogeneous disturbances of metabolism for which the main finding is chronic hyperglycemia. The cause is either impaired insulin secretion or impaired insulin action or both [10]. Diabetes mellitus (DM) is a common, yet serious disease with substantial health concerns [11,12] The prevalence of DM in Saudi Arabia is on the rise. Diabetic patients constitute a subcategory of patients who undergo emergency general surgery procedures. The perioperative management of diabetic patients must include proper control of their blood sugar and adjustment of their diabetic medications in order to minimize complications [13].
The postoperative complications in emergency general surgery have only been addressed in a few studies, with little specific information available for the Middle East and Saudi Arabia and for the subgroup of diabetic patients [8]. The aim of this study was to identify whether the outcome of these procedures in diabetic patients is different than those who are not diabetic.

More than half of the patients in this study had diabetes, which corresponds to the rising prevalence of the disease in Saudi Arabia and the whole world. This also means that a major proportion of emergency general surgery procedures are performed on diabetic patients. Researching this patient population, with attention to any difference in their needs based on outcomes is particularly important. 
Our findings in Table 3 of the study prove that the odds of having DM is higher in patients who have other chronic diseases such as IHD, heart failure, cerebrovascular disease, HTN, CRD, and cancer. This not surprising since DM is known to lead to different chronic derangements of other body systems [14].

The results of our study demonstrate an association of DM with two of the important postoperative indicators of morbidity; ICU admission and hospital re-admission. We note in the Table 4 that differences in individual systemic postoperative complications were not statistically significant between diabetic and non-diabetic patients. Thus, the statistically higher ICU admissions and hospital re-admission might indicate in this case that the postoperative complications diabetic patients develop are more severe to the extent these patients more frequently require ICU admissions and/or hospital re-admission.

Although some previous research work analyzed the outcomes of some special subsets of patients undergoing emergency surgery such as elderly patients [15], we did not come across articles specifically studying the outcome of diabetic patients undergoing such procedures.

The results of our study supplement the current understanding of the effect of DM on patients' outcome after emergency general surgeries. Those findings remind health care providers to pay special attention to diabetic patients when they present emergently with an acute surgical problem. In these situations, physicians and nurses should provide prompt and watchful care to this subset of patients attempting to avoid complications. Early recognition and intervention for any perioperative complications may help reduce ICU admissions and readmission to hospitals after initial discharge which might not only help patients but can reduce health care costs as well.

In spite of the rational results of our study, however, it has some limitations. The study was conducted retrospectively and in a single center which might limit the generalization of its results. Therefore, multi-center prospective studies are suggested to further support the findings of the current study.

\section{Conclusion}

There are significant associations of the diagnosis of diabetes and worse postoperative outcomes in patients undergoing emergency general surgery procedures. Health care providers should give special attention as well as prompt and watchful perioperative care for this patients' population.

\section{Acknowledgement}

The author would like to acknowledge Dr. Khaled Taha and Dr. Khaled Jan for their efforts and help in data collection. He also acknowledges Mr. Salah Barnawi for his work on statistical analysis.

\section{References}

1. Lushiku EB. Diabetic foot. Rev Med Brux 2006; 27: S315S323.

2. Won JC, Kwon HS, Kim CH, Lee JH, Park TS, Ko KS, Cha BY. Prevalence and clinical characteristics of diabetic peripheral neuropathy in hospital patients with Type 2 diabetes in Korea. Diabet Med 2012; 29: e290-e296.

3. Alotaibi A, Perry L, Gholizadeh L, Al-Ganmi A. Incidence and prevalence rates of diabetes mellitus in Saudi Arabia: An overview. J Epidemiol Glob Health 2017; 7: 211-218.

4. Kim SM, Kim YH, Jun YJ, Yoo G, Rhie JW. The effect of diabetes on the wound healing potential of adipose-tissue derived stem cells. Int Wound J 2016; 13: 33-41

5. Oliveira MF, Viana BJF, Matozinhos FP, Silva MMSD, Pinto DM, Moreira AD, Velásquez-Meléndez G, Gomes FSL. Lower limb wounds in diabetic and non-diabetic patients: survival analysis. Rev Gaucha Enferm 2019; 40: e20180016.

6. Al-Niaimi AN, Ahmed M, Burish N, Chackmakchy SA, Seo S, Rose S, Hartenbach E, Kushner DM, Safdar N, Rice L, Connor J. Intensive postoperative glucose control reduces the surgical site infection rates in gynecologic oncology patients. Gynecol Oncol 2015; 136: 71-76.

7. Greco G, Ferket BS, D'Alessandro DA, Shi W, Horvath KA, Rosen A, Welsh S, Bagiella E, Neill AE, Williams DL, Greenberg A, Browndyke JN, Gillinov AM, Mayer ML, Keim-Malpass J, Gupta LS, Hohmann SF, Gelijns AC, O'Gara PT, Moskowitz AJ. Diabetes and the association of postoperative hyperglycemia with clinical and economic outcomes in cardiac surgery. Diabetes Care 2016; 39: 408-417.

8. Ingraham AM, Cohen ME, Bilimoria KY, Raval MV, Ko CY, Nathens AB, Hall BL. Comparison of 30-day outcomes after emergency general surgery procedures: Potential for targeted improvement. Surgery 2010; 148: 217-238.

9. World Health Organization. Obesity: Preventing and managing the global epidemic. Report of a WHO Consultation WHO Technical Report 2000; 894: 1-252.

10. American Diabetes Association. Diagnosis and classification of diabetes mellitus. Diabetes Care 2009; 32: S62-S67.

11. DeFronzo RA, Ferrannini E, Groop L, Henry RR, Herman WH, Holst JJ, Hu FB, Kahn CR, Raz I, Shulman GI, Simonson DC, Testa MA, Weiss R. Type 2 diabetes mellitus. Nat Rev Dis Primers 2015; 1: 15019.

12. Katsarou A, Gudbjörnsdottir S, Rawshani A, Dabelea D, Bonifacio E, Anderson BJ, Jacobsen LM, Schatz DA, Lernmark Å. Type 1 diabetes mellitus. Nat Rev Dis Primers 2017; 3: 17016.

13. Peters A, Kerner W. Perioperative management of the diabetic patient. Exp Clin Endocrinol Diabetes 1995; 103: 213-218.

14. Schlienger J. Type 2 diabetes complications. Presse Med 2013; 42: 839-848. 
15. Dowgiałło-Wnukiewicz N, Kozera P, Lech P, Rymkiewicz P, Michalik M. Emergency surgery in older patients. Wideochir Inne Tech Maloinwazyjne 2019; 14: 182-186.

\section{*Correspondence to}

Dr. Abdulmalik Altaf

Associate Professor

Department of Surgery

Faculty of Medicine

King Abdulaziz University

Jeddah

Saudi Arabia

altaf12345@yahoo.com 